\title{
Vector Control for Mosquito in Ethiopia: A Review Article
}

\section{Tesfahuneygn G* and Gebreegziabher G}

Tigray health research institute, Mekelle, Ethiopia

*Corresponding author: Gebrehiwet Tesfahuneygn, Tigray health research institute, Mekelle, Ethiopia, Email: gtlab2006@gmail.com

\section{Review Article \\ Volume 2 Issue 3}

Received Date: November 19, 2018

Published Date: November 30, 2018

\begin{abstract}
Vector transmitted diseases remains a serious public health burden in the world. The current core methods used for malaria vector control interventions worldwide are indoor residual spraying (IRS) and long-lasting insecticidal nets, with larval source management (LSM) applicable in certain settings where mosquito breeding sites are few, fixed and findable. Mosquitoes transmit many diseases including malaria, dengue fever, Japanese encephalitis virus, West Nile virus, yellow fever virus and filariasis. Of these, malaria transmitted primarily by An. gambiae, dengue transmitted by Aedes aegypti, and lymphatic filariasis transmitted by $C$. quinquifasciatus are the most devastating problems in terms of the global number of people affected. Insecticide-treated bed nets and indoor residual spraying have been widely used as front-line tools against malaria vectors in endemic African regions. These preventive measures are highly effective against malaria vectors, which prefer to bite and rest inside the rooms. Some of the adulticide used for mosquito control include products derived from microorganisms, plants or minerals, synthetic molecules, organophosphates, some natural pyrethrins, or synthetic pyrethroids.
\end{abstract}

Keywords: Mosquito; Malaria; Vector control

Abbreviations: IRS: Indoor Residual Spraying; LSM: larval source management; PMI: President's Malaria Initiative; LLINs: long-lasting insecticidal nets.

\section{Introduction}

Malaria remains a serious public health burden in endemic regions. The World Health Organization (WHO) estimates that there were 214 million new cases of the disease and more than 445,000 malaria-related deaths in 2016, with $91 \%$ of these occurring in Africa [1]. As there are no commercially available vaccines against this disease, vector control remains crucial to reduce disease transmission. Vector control strategies have traditionally focused on killing mosquitoes using a variety of insecticides. Environmental management (through reduction or removal of mosquito breeding sites) has often been used alongside chemical or microbiological ovicides, larvicides, and pupicides areas where endemic mosquito-borne diseases occur. The Global Fund and the President's Malaria Initiative (PMI) are supporting the scaling up of long-lasting insecticidal nets (LLINs) and indoor residual spraying (IRS) in many endemic African countries [2,3]. Long-lasting insecticidal nets (LLINs) have contributed significantly to the success of malaria control in such malaria endemic countries. Since 2000, malaria mortality rates have fallen by $66 \%$ among all age groups and by $71 \%$ among children under 5 years of age [4]. According to WHO estimates, the incidence of malaria (i.e. the rate of new malaria cases) fell by $18 \%$ between 2010 and 2016 [1].

The current core methods used for malaria vector control interventions worldwide are indoor residual 


\section{Journal of Infectious Diseases \& Travel Medicine}

spraying (IRS) and long-lasting insecticidal nets, with larval source management (LSM) applicable in certain settings where mosquito breeding sites are few, fixed and findable [5,6]. Historically, IRS has been the primary intervention method in vector control efforts $[5,6]$. Since its introduction as a vector control tool in 1945, IRS has proven successful in reducing the prevalence and incidence of malaria by reducing the level of transmission through killing or repelling malaria vectors.

\section{Diseases Spread by Mosquitoes}

Mosquitoes transmit many diseases including malaria, dengue fever, Japanese encephalitis virus, West Nile virus, yellow fever virus and filariasis. Of these, malaria transmitted primarily by An. gambiae, dengue transmitted by Aedes aegypti, and lymphaticfilariasis transmitted by C. quinquifasciatus are the most devastating problems in terms of the global number of people affected. Approximately half of the world's population are at risk of malaria, with 225 million cases being recorded in 2009 [7]. Dengue fever, a flavivirus transmitted by Aedes mosquitoes (mainly Aedes aegypti, and Aedes albopictus), is an increasingly serious public health problem in over 100 countries with some 2.5 billion people at risk [8]. Culex quinquefasciatus is a major biting nuisance in the urban tropics, and is a vector for West Nile virus in addition to lymphatic filariasis, which affects 120 million people worldwide, and can lead to genital damage and elephantiasis. Apart from the obvious health issues, the economic and environmental costs are high. Such diseases have detrimental effects on fertility, population growth, saving and investment, worker productivity and absenteeism, premature mortality and medical costs. Countries with high malaria transmission have had historically lower economic growth than countries without malaria.

Insecticide-treated bed nets (ITNs) and indoor residual spraying (IRS) have been widely used as frontline tools against malaria vectors in endemic African regions [9]. These preventive measures are highly effective against malaria vectors, which prefer to bite and rest inside the rooms [10]. Use of ITNs and IRS over the last decade has led to a significant decrease in malaria transmission in many areas of sub-Saharan Africa.

Malaria vector control strategies target both the immature and adult stages of Anopheles populations. Before World War II, anti-larval malaria control was the preferred strategy to control malaria. The intervention strategies predominantly included physical elimination of mosquito breeding sites, biological control using larvivorous fish and chemical larviciding with Paris green
[11]. Today, larval control is used and promoted to limit the development of Anopheles larvae in breeding sites [12] using biological larvicides such as Bacillus thuringiensis israelensis (bti) that were first developed 30 year ago [13]. However, larval control is not particularly effective, especially in case of some Anopheles species for which breeding sites are extremely numerous and inaccessible.

\section{Larval Source Management}

Larval source management (LSM) refers to the targeted management of mosquito breeding sites, with the objective to reduce the number of mosquito larvae and pupae. LSM is only recommended as a supplementary malaria vector control measure; it should not be used to replace core vector control interventions, such as long lasting insecticidal nets (LLINs) and indoor residuals praying (IRS). LSM includes 1)habitat modification, which means a permanent alteration to the environment, e.g. land reclamation or surface water drainage;2) habitat manipulation, which refers to a recurrent activity e.g. water-level manipulation, flushing of streams, the shading or exposure of habitats;3) larviciding, which involves the regular application of a biological or chemical insecticide to water bodies; and 4) biological control, which refers to the introduction of natural predators into water bodies, for example predatory fish or invertebrates. In general, LSM programmes need to be fully tailored to local environmental conditions and should be based on comprehensive feasibility and cost-effectiveness studies. Similarly to core vector control interventions, the management of larval habitats is a major financial and technical undertaking, requiring both community support and long-term political commitment.

Adulticides technique is usually less efficient for mosquito control. However, it is the only way to kill adult mosquitoes and is the last line of defense in reducing mosquito populations. Some of the adulticide used for mosquito control include products derived from microorganisms, plants or minerals, synthetic molecules, organophosphates, some natural pyrethrins, or synthetic pyrethroids [14].

\section{Chemical Insecticides}

Chemical insecticides have represented the most widely method used to control mosquito-borne vectors. However, the effects of chemical insecticides on mosquito vector populations are usually transitory because vectors can rapidly develop resistance against them. Some of the disadvantages that generates when using only chemical products are 


\section{Journal of Infectious Diseases \& Travel Medicine}

- The selection of new insecticide resistance in pest populations

- The resurgence of already treated populations

- The generation of waste, risks, and legal complications

- The destruction of beneficial species

- The high costs in equipment, labor, and material

In addition, the highly toxic and non-biodegradable properties of insecticides and waste generated in soil, water, food, and crops that affect public health are additional reasons to search new methods to help solve the problems caused by chemical insecticides [15] Consequently, the concept of integrated control arises, a method in which pest and diseases control is performed using chemicals, useful organisms, and cultural practices.

The progress of science and the chemical industry in the nineteenth century, with the discovery of DDT, made possible the development and emergence of new conventional insecticides or so-called of synthesis [16]. The most used of these insecticides of synthesis are modulators of sodium channels (organochlorines, pyrethroids, and pyrethrins), acetylcholinesterase inhibitors (carbamates and organophosphates), and the chloride channel antagonists regulated by the gammaamino butyric acid or also known as GABA (organochlorinecyclodiene and phenylpyrazoles).

Using these conventional insecticides gave positive results against in sects disease vectors at first. However, due to its massive use, insects soon began to develop resistance to them. Thus, an insecticide that initially was effective, just being useless in the long term. In response to this problem, new-generation insecticides also called bio rational insecticides have been developed, whose research strategy is based on a good understanding of the physiological processes or mechanisms specific communication of insects, and in obtaining agents that are able to affect them. These products are divided into the following: those who are analogs of juvenile hormone and molting, inhibitors tissue formation, pheromones, insecticides that prevent hatching, and biological insecticides [17].

\section{Plants and their Derivates}

For centuries, nature has created several active substances that, when applied correctly, can control insect pests such as mosquito in an efficient manner. The use of plants by man with insecticide purposes dates back to early human history. Due to their environmental advantages, the use of insecticides of vegetable origin in pest management has been increasing [18]. Among plants with potential activity against mosquitoes, Nim or Neem (Azadirachta indica) causes stunted growth, loss of appetite, reduction of fertility, molting disorders, morphological defects, and behavioral changes [19]. Moreover, it has been demonstrated that raw or partially purified plant extracts are most effective for mosquito control in place of the purified compounds or extracts [20]. The snuff (Nicotiana tabacum) is used, thanks to its insecticide and insect repellent action, where nicotine acts on the nervous system of insects through breathing, ingestion, and contact [21]. Other plants from which oils are extracted are garlic (Ocimum basilicum) and cinnamon (Cinnamomum osmophloeum), which have been shown to have insecticidal properties against larvae and adults of A. albopictus, Culex quinquefasciatus, and Armigeres subalbatus.

\section{Biological Agents}

Among biological agents used for mosquito control can be mentioned derivatives of viruses, bacteria, and fungi. Entomopathogenic virus spreads from one insect generation to the next causing paralysis and eventually death on mosquito larvae being more effective in the first stage of development [22]. Within bacteria, only reports of Bacillus thuringiensis, B. sphericus, and B. popilliae with possibilities to exercise control over dipterans insects currently exist. These bacteria, during the sporulation process, produce protein crystals with insecticidal effect and/or some toxins with the same effect [23]. Bacillus initially causes diarrhea and intestinal paralysis in mosquito, giving rise to a decrease of body movements, convulsions, and general paralysis. Internally, within the mosquito stomach, B. thuringiensis releases toxic crystals that paralyze the insect gut stopping peristalsis, causing that the insect stop feeding and die by starvation. Within the gut, bacteria multiply until they break the epithelium and invade the rest of the insect body. However, its use for mosquito control is scarce and presents some drawbacks as its duration in the environment is limited, its dispersion is rather inefficient, and the susceptibility to bacterial infection in the pest population is very heterogeneous. There are very sensitive individuals and other highly resistant. Fungi are other microorganisms that maybe used to control mosquito vectors, of which 400 species are known with insecticide potential. About 20 of them have been given more attention, including those in the Lagenidium, Entomophaga, Neozygites, Entomophtora, Erynia, Aschersonia, Verticillium, Nomuraea, Hirsutella, Metarhizium, Beauveria, and Paecilomyces genera [24]. Although, entomopathogenic fungi are not as specific as bacteria or viruses, spores persist and infect insect successive generations, so that when the infection is 
established, its effects can last several years. Infection occurs by adhesion of the spores on the insect cuticle, where these germinate and penetrate the cuticle leading to insect colonization by mycelium. Cuticle penetration occurs through the use of an enzyme complex that the fungi use to feed. The entomo pathogenic fungus most used in controlling mosquito infestations is Beauveriabassiana, which produces various active ingredients such as beauvericin [25].

The biological control of mosquito larvae with predators and other biological control agents could be a more effective and environmentally friendly strategy, thus avoiding the use of synthetic chemicals and the consequent environmental damage [26]. Among them, some insects and vertebrates such as fish, amphibians, and some mammals have the potential to control mosquito disease-vector populations. Within vertebrates, amphibians, bats, and fish have been used to control populations of mosquito. For example, using larvivorous fish species, control of mosquito larvae in deposits used to store water has been achieved [27]. Moreover, bats are responsible for capturing flying insects such as mosquitoes at night; similarly, toads and frogs consume large numbers of insects, slugs, worms, and other invertebrates [28]. However, the use of frogs and tadpoles for disease vector control is still largely unexplored.

\section{Conclusions}

Mosquito-borne diseases remain a major cause of morbidity and mortality across the tropical regions. The current core methods used for malaria vector control interventions worldwide are indoor residual spraying and long-lasting insecticidal nets, with larval source management applicable in certain settings where mosquito breeding sites are few, fixed and findable.

\section{Competing Interests}

The authors declare that they have no competing interests.

\section{Authors' Contribution}

GT and GG wrote and edited the manuscript. All authors read and approved the final manuscript.

\section{References}

1. WHO (2017) World malaria report 2017. World Health organization, Geneva.
2. Bhattarai A, Ali AS, Kachur SP, Mårtensson A, Abbas $A K$, et al. (2007) Impact of artemisinin-based combination therapy and insecticide-treated nets on malaria burden in Zanzibar. PLoS Medicine 4.

3. Ceesay SJ, Casals-Pascual C, Nwakanma DC, Walther M, Gomez-Escobar N, et al. (2010) Continued decline of malaria in The Gambia with Implications for elimination. PLoS One 5: e12242.

4. WHO (2016) World malaria report 2016. World Health Organization, Geneva.

5. WHO (2014) World Malaria Report 2014. World Health Organization, Geneva.

6. WHO (2012) Global plan for insecticide resistance management in malaria vectors: World Health Organization Global Malaria Programme.

7. WHO (2010) World Malaria report. World Health Organization, Geneva, Switzerland.

8. WHO (2008) Dengue and dengue hemorrhagic fever. World Health Organization.

9. Hemingway J, Ranson H, Magill A, Kolaczinski J, Fornadel C, et al. (2016) Averting a malaria disaster: Will insecticide resistance derail malaria control? The Lancet 387(10029): 1785-1788.

10. Scott TW, Takken W (2102) Feeding strategies of anthropophilic mosquitoes result in increased risk of pathogen transmission. Trends Parasitol 28(3): 114121.

11. Mabaso MLH, Sharp B, Lengeler C (2004) Historical review of malarial control in southern African with emphasis on the use of indoor residual housespraying. Trop Med Int Health 9(8): 846-856.

12. Dambach P, Schleicher M, Stahl H-C, Traoré I, Becker $\mathrm{N}$, et al. (2016) Routine implementation costs of larviciding with Bacillus thuringiensisis raelensis against malaria vectors in a district in rural Burkina Faso. Malar J 15(1): 380.

13. Becker N, Margalit J, Entwistle PF, Cory JS, Bailey MJ, et al. (1993) Use of Bacillus thuringiensisis raelensis against mosquitoes and blackflies. Bacillus Thuringiensis. Bacillus thuringiensis, an environmental biopesticide: Theory and practice. Wiley \& Sons, Chichester, pp: 147-170.

14. Fathy KH (2012) Ecosmartbiorational insecticides: alternative insect control strategies. In: Insecticides- 


\section{Journal of Infectious Diseases \& Travel Medicine}

Advances in Integrated Pest Management. In Tech Rijeka, pp: 1-46.

15. Koul O, Walia S, Dhaliwal GS (2008) Essential oils as green pesticides: potential and constraints. Biopesticide International 4: 63-84.

16. Díez DM (2013) Efecto Del Methoprene sobre la metamosfosis de la cucaracha, Blattellagermanica. Vizcaya: Universidad Del País Vasco, pp: 1-24.

17. Mamatha DM, Kanji VK, Cohly H, Rajeswara RM (2008) Juvenile hormone analogues, methoprene and fenoxycarb dose dependently enhance certain enzyme activities in the silkworm Bombyxmori(L). International Journal of Environmental Research Public Health 5(2): 120-124.

18. Leyva M, Marquetti del MC, French L, Montada D, Tiomno 0, et al. (2013) Efecto de unaceite de trementina obtenido de Pinus tropicalis Moreletsobre la biología de unacepa de Aedes (Stegomyia) aegypti Linnaeus, 1762 resistente a insecticidas. Anales de Biología 35: 75-84.

19. Wandscheer CB, Duque JE, da Silva MAN, Fukuyama Y, Wohlke JL, et al. (2004) Larvicidal action of ethanolic extracts from fruit endocarps of Meliaazedarach and Azadirachta indica against the dengue mosquito Aedes aegypti. Toxicon 44: 829-835.

20. Abdelouaheb A, Nassima R, Noureddine S (2009) Larvicidal activity of a neem tree extract (Azadirachtin) against mosquito larvae in the Republic of Algeria. Biological Sciences 2: 15-22.
21. Brechelt A (2004) Manejo Ecológico de Plagas y Enfermedades, Red de Acción en Plagicidasysus Alternativaspara América Latina (RAP-AL). Santiago de Chile, Chile, pp: 4-36.

22. Primo YE (1991) Mundi prensa ed. Ecología química. Nuevos métodos de lucha contra insectos. Madrid, pp: 191.

23. Badii MH, Abreu JL (2006) Control biológicouna forma sustentable de control de plagas. Daena: International Journal of Good Conscience 1: 82-89.

24. Van Driesche RG, Bollows TS (2012) Biological Control. Chapman \& Hall, New York, pp: 539.

25. García GC, Tamez GP (2012) Mercado de bio insecticide as en México. Curso de agriculture aorgánica y sustentable. Fundación Produce Sinaloa, pp: 99-114.

26. Kumar R, Hwang JS (2006) Larvicidal Efficiency of Aquatic Predators: A Perspective for Mosquito Biocontrol. Zoological Studies 45(4): 447-466.

27. Connelly CR, Bolles E, Culber D, De Valerio J, Donahoe M, et al. (2014) Florida Resident's Guide to Mosquito Control, Integrated Pest management for Mosquito Reduction around Homes and Neighborhoods. University of Florida, USDA-NIFA, pp: 22-37.

28. Mahr LD, Whitaker P, Ridgway N (2008) Biological control of insects and mites: an introduction to beneficial natural enemies and their use in pest management, UW Extension, Wisconsin Madison, pp: 116. 